\title{
Sex Diserimination Against the American Working Woman
}

\author{
TERESA LEVITIN \\ ROBERT P. QUINN \\ GRAHAM L. STAINES \\ University of Michigan
}

The concept of discrimination is inextricably linked to a particular ideology or set of values. Ideologies delineate desirable social conditions; discrimination refers to departures from ideological prescriptions. More specifically, discrimination may be defined as the withholding of rewards or facilities on the basis of allocative criteria inconsistent with a particular ideology. Discrimination refers to providing individuals with fewer rewards or facilities than are legitimately deserved; favoritism, to providing more rewards or facilities than are legitimately deserved.

Of specific concern here is occupational sex discrimination. The discrepancy between ideology and reality with

Authors' Note: This research was supported by a contract with the Employment Standards Administration of the U.S. Department of Labor. Interpretations or viewpoints stated in this report do not necessarily represent the official position or policy of the Department of Labor. Collaborating in the analysis of the data presented in this report were Margaret McCullough Black, J. Thad Barrowe, Jody Crowley, and Caren Cole. 
regard to occupational rewards and, particularly, the differential allocation of these rewards to female and male workers are the central issues of this paper. Excluded is the problem of access discrimination-discrimination, that women may face in terms of the availability to them of particular jobs. Instead, attention is devoted only to treatment discrimination, discrimination that women may confront once they have obtained jobs. Excluded also is any consideration of those who do the discriminating, of their motives and rationalizations (Quinn et al., 1968). The focus is exclusively upon those who face discrimination.

Different ideologies generate different definitions and measures of discrimination. For each ideology, an acceptable or legitimate set of criteria on which to base differential rewards must be made explicit by the investigator so that discrimination may be measured in terms of departure from these criteria. In American society, particularly in economic life, the dominant ideology is an achievement ideology according to which rewards ought to be based on merit or performance. Another ideology, reflected in Marxist writings, economic liberalism, and support for government spending on social welfare is a need ideology according to which rewards ought to be based on need rather than on performance.

This study examines occupational sex discrimination within the framework of the pervasive achievement ideology, an ideology chosen not because of the authors' adherence to it but rather because it is generally used to justify sex differentials in occupational rewards. According to Dornbusch (1966), for example, some justify the inequality of income between men and women by claiming that women are more likely to be sick, to be absentees, and to quit their jobs. Aside from the factual errors in these claims, the form of argument demonstrates how ideological appeals may be offered to justify inequalities. Alternatively, sex differentials in occupational rewards are justified by some in terms of a 
need ideology. Since proportionately more men than women are primary wage earners, it is sometimes claimed that men need more and therefore should earn more.

In short, this study examines how consistently occupational rewards are allocated on the basis of achievement and whether observed sex differences in rewards may be attributed to legitimate achievement factors. Even though the dominant business ideology is that achievement ought to determine the distribution of occupational rewards, it rapidly emerges that sex discrimination is a partial reason that reality often fails to reflect this ideology.

\section{STRATEGIES FOR INFERRING DISCRIMINATION}

While in principle discrimination can be readily defined in terms of a particular ideology, its detection must take several factors into account:

(1) On the basis of a selected ideology, the legitimate factors in the allocation of rewards or facilities should be specified.

(2) It is likewise important to attend methodologically to these legitimate control variables.

(3) The list of patently illegitimate determinants of rewards needs to be complete.

(4) Measures of discrimination should not simply identify discrimination against aggregates of individuals. They should also detect individual differences in the amount of discrimination encountered. Measures of individual differences in degree of discrimination are essential lest examining the effects of discrimination be restricted to ecological analyses.

\section{RESEARCH QUESTIONS}

This study applied these four considerations to several questions concerning discrimination against American working women: 
(1) To what extent are working women denied occupational rewards on bases other than those justified by the achievement ideology?

(2) What are the demographic and occupation distributions of reward inequalities among major segments of the national population of working women?

(3) To what extent are these objectively measured inequities related to reports of perceived sex discrimination?

(4) To what extent are reward inequities related to the satisfaction of women with their jobs?

\section{METHOD}

Data were obtained from a survey of American workers conducted by the Survey Research Center of the University of Michigan late in 1969. The principal aims of the survey were to determine some of the problems that workers faced, to develop measures of job satisfaction suitable for use with samples of workers in heterogeneous occupations, and to assess the effects of working conditions on both the job satisfaction and the mental health of workers. Basic univariate and bivariate tables are presently available (Quinn et al., 1971), and a series of reports on specific substantive areas, including the status of working women, are currently in preparation. The analysis reported here is a preliminary part of the forthcoming report on women.

\section{SAMPLE}

The sample was a national probability sample of persons who were living in households, were sixteen years old or older, and were working for pay twenty hours a week or more. Data were obtained through personal interviews with all eligible workers in a household. Since each worker therefore had an equal probability of being selected, the data were self-weighting. The full sample included 539 women and 993 men. A comparison between the demographic and 
occupational characteristics of the sample and those of larger-scale government surveys is presented in Quinn et al. (1971: 25-28). The analysis reported below excluded three groups of workers: self-employed workers; part-time workers, defined as those working less than 35 hours a week; and workers who were seasonally or otherwise irregularly employed during the year. School teachers were not regarded as seasonally employed. After these exclusions, the remaining sample consisted of 351 women and 695 men. For some analyses, the sample of men was further randomly divided into two half-samples.

\section{MEASURES}

Occupational rewards. Two measures of occupational rewards were employed:

(1) Total annual income from the worker's primary job before taxes or other deductions. (Where a worker held more than one job, all questions in the interview were asked with reference to the job on which the worker spent the greatest number of hours.)

(2) Quality of work, a summary index based upon 70 questions dealing with how good each worker's job was. Among the areas covered by the index were income, health and safety, hours, transportation to and from work, interpersonal relations on the job, job security, and the content of the worker's job.

Objective discrimination. Objective sex discrimination was defined operationally as the difference between the amount of each of the above two rewards each woman was receiving and the amount she would be expected to receive on the basis of achievement factors alone. Ideally, achievement factors should have been assessed by some objective measure of each woman's past or anticipated performance. This was clearly impossible, given the occupational heterogeneity of the sample. Instead, several predictor variables were selected that were indirect estimators of achievement. These factors were: education, tenure with one's employer, tenure on one's 


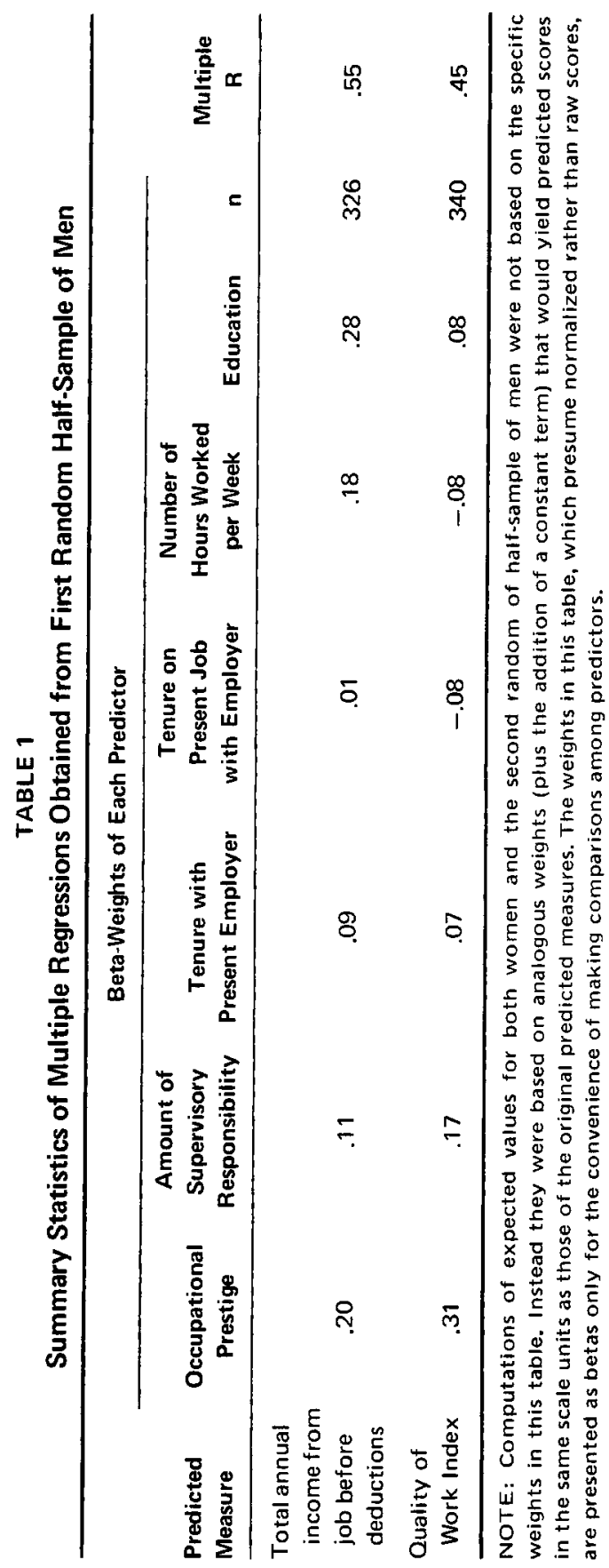


specific job with that employer; number of hours worked each week; amount of supervisory responsibility; and occupational prestige as measured by the Duncan scale (Reiss et al., 1961). The choice of appropriate predictors was somewhat arbitrary, reflecting the authors' understanding of the achievement ideology. For example, whether or not job tenure was an appropriate factor for determining occupational income depends upon how tenure is conceived. It was decided to assume that longer tenure may lead to the acquisition of additional experience and skills and thereby constitutes an appropriate basis for assigning occupational rewards.

Under the assumption that sex discrimination was not operative for men, multiple regressions were obtained for a random half-sample of the men to determine the optimal weighting of these selected achievement variables in predicting both reward measures. The results of these multiple regressions are presented in Table 1 . On the basis of the weights provided by the multiple regressions computed on the first random half-sample of men, expected values on both reward measures were computed for the sample of women and the second random half-sample of men. Three measures of objective discrimination were then computed for each occupational reward:

(1) Discrepancy equals observed value minus expected value. This measure indicated the amount of reward discrepancy without any reference to the absolute level of either expected or observed values. The scale units were in dollars of annual income and on an arbitrary scale for the Quality of Work Index. A negative sign affixed to any discrepancy indicates that the worker received less of the reward than would be expected on the basis of the legitimate achievement factors alone.

(2) Ratio of discrepancy to expected value equals:

$$
\left[\frac{\text { observed value }- \text { expected value }}{\text { expected value }}\right] \times 100
$$


Applied to women in the sample, this ratio describes the amount of rewards each woman was deprived relative to what she would have been getting had she been a man (i.e., relative to the expected values based on the multiple regression for men). Subtracted from $100 \%$, it indicates what percentage of a man's income each woman received.

(3) Ratio of discrepancy to observed value equals:

$$
\left[\frac{\text { observed value }- \text { expected value }}{\text { observed value }}\right] \times 100
$$

Applied to women in the sample, this ratio describes the amount of rewards each woman was deprived relative to what she was in fact receiving.

Perceived discrimination. Each woman was asked, "Do you feel in any way discriminated against on your job because you are a woman?"

Job satisfaction. Several measures of job satisfaction were used to measure the possible effects of objective sex discrimination upon the job-related attitudes of women. A previous factor analysis of the importance to workers of selected aspects of their jobs (Quinn et al., 1971) identified five independent dimensions of what workers wanted from their jobs, dimensions which were employed in the present analysis. These dimensions were: (a) satisfaction with the comfort aspects of the job (convenient hours, pleasant physical surroundings, and demands that were neither heavy nor conflicting); (b) satisfaction with the challenge provided by the job (opportunity to do interesting, challenging, and self-developing work); (c) satisfaction with financial rewards (pay, fringe benefits, and job security); (d) satisfaction with co-workers; (e) satisfaction with resources for doing the job (equipment, information, clear assignments, and competent supervision). Also employed in the analyses was Jobsat '70 (Quinn et al., 1971), an index of overall job satisfaction which included all the 23 items from the above five indices. 


\section{RESULTS}

The data below are organized according to their relevance to the four questions posed earlier in this paper.

(1) To what extent are working women denied occupational rewards on bases other than those justified by the achievement ideology? The mean of the observed-expected discrepancy in total annual income for women was $-\$ 3,458$ $(\mathrm{SD}=\$ 2,200 ; n=323)$; for the second random half-sample of men, this mean score was $-\$ 27(\mathrm{SD}=\$ 4,523 ; \mathrm{n}=331)$. Sex differences in these discrepancy scores, computed according to formula 1 above, indicated the extent to which the achievement ideology was differentially applied to women and to men. The discrepancy between the income women should have received based on the multiple regression equation and the income they in fact received was significantly different from the comparable discrepancy for the men $(t=12.287, p<.001)$.

Figure 1 shows graphically the distribution of total annual income discrepancies of all women in the study's sample and the second random half-sample of men. The figure indicates that $50.3 \%$ of the women in the sample had total annual income discrepancies ranging from $-\$ 3,000$ through $\$ 5,999$; the comparable percentage for men was only $16.2 \%$. The mean annual income of $94.9 \%$ of the women was less than the amount they should have received on the basis of the achievement criteria. Fifty percent, not zero, forms the reference point against which this $94.9 \%$ figure should be evaluated, since in a population not discriminated against (e.g., the male sample), roughly $50 \%$ should receive more and $50 \%$ should receive less than their expected scores based on the achievement criteria.

Sex differences in the distribution of the discrepancy scores on the Quality of Work Index were less extreme than those based on annual income. The mean score for women was $-.11 ;(\mathrm{SD}=.30 ; \mathrm{n}=341)$. For the second random 


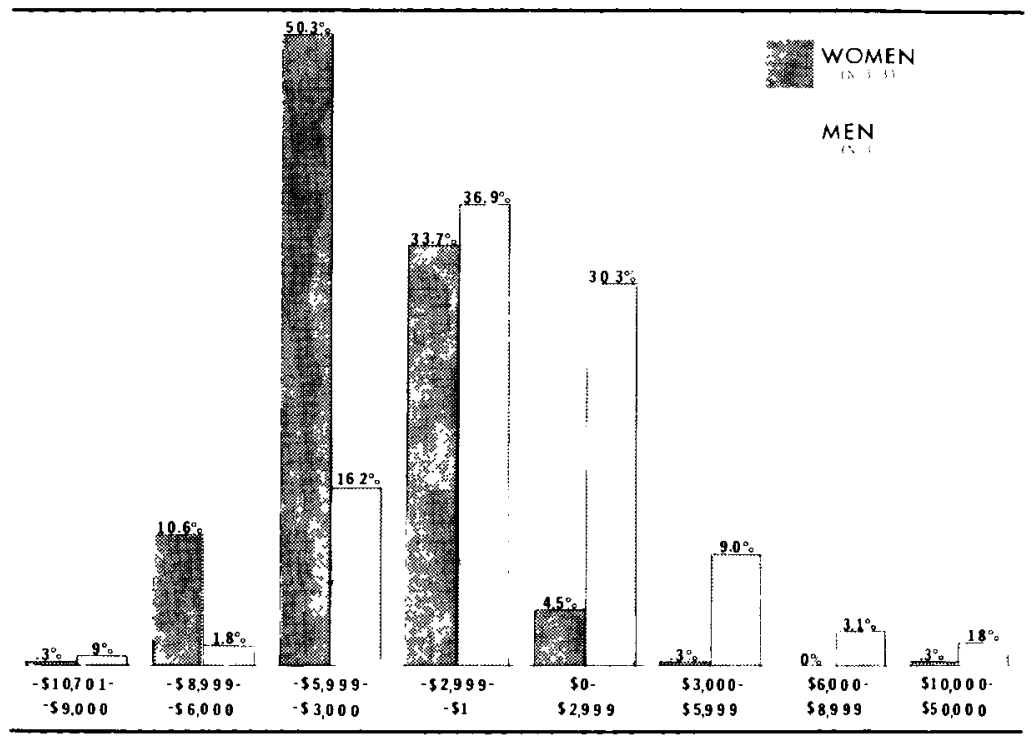

Figure 1: PERCENTAGE DISTRIBUTION OF TOTAL ANNUAL INCOME DISCREPANCIES FOR WOMEN AND SECOND RANDOM HALFSAMPLE OF MEN

half-sample of men, the mean score was $-.02(\mathrm{SD}=.31 ; \mathrm{n}=$ 346). Nevertheless women had significantly greater negative discrepancies than had men $(t=3.870, p<.001)$.

The discrepancy scores just described failed to take into account the magnitude of the discrepancy relative to the absolute level of a worker's income, either observed or expected. By dividing each woman's income discrepancy by her present income level (formula 3), it was possible to estimate the percentage of her current income that each woman "lost" by virtue of being a woman. The median figure that resulted was $71 \%$. In other words, the average woman should have received $71 \%$ more than her current income to make her income equivalent to a man with the same scores on the achievement variables.

The expected values of the income measure when applied to women indicated how much each woman would have earned had the achievement indicators built into the multiple 
regression equation been equally operative for men and for women. Using the percentage figure obtained from formula 2 , it was possible to calculate the percentage of a man's estimated income that an equally qualified woman received. According to this estimate, the median woman received $58 \%$ of a comparable man's income.

(2) What are the demographic and occupational distributions of reward inequalities among major segments of the national population of working women? In order to answer this question, the sample of women was dichotomized into (a) those with total annual income discrepancies that were positive (i.e., indicative of favoritism), zero, or had negative values ranging between $-\$ 1$ through $-\$ 3,499$, and (b) those with discrepancies of $-\$ 3,500$ or more. The percentages of women in the latter higher income discrepancy category are presented in Table 2 for selected demographic and occupational classifications.

Like sex, the two demographic variables selected-race and age-represent illegitimate bases of occupational reward allocation. The data indicated that although a somewhat larger percentage of white women than of black women had high discrepancy scores, the difference was not significant. The association between age and discrepancy scores was curvilinear, with both the youngest (16-29 years old) and oldest ( 55 years old or older) women being more likely than women of other ages to have high discrepancy scores.

The distribution of the high income discrepancies was also examined with relation to the five characteristics of each woman's occupation listed in Table 2. Discrimination as reflected in the income differentials was greatest among: white-collar workers; those employed in professional, technical, managerial, clerical, and sales work; those in trade, services, finance, insurance, and real estate; those who did not belong to a union; and those in comparatively small establishments (i.e., where less than 500 employees worked). 
TABLE 2

Percentage of Women in Selected Demographic and

Occupational Categories with Total Annual

Income Discrepancies of $-\$ 3,500$ or More

\begin{tabular}{|c|c|c|c|c|}
\hline $\begin{array}{l}\text { Demographic or } \\
\text { Occupational Category }\end{array}$ & Percentage & Base n & df & $x^{2}$ \\
\hline $\begin{array}{l}\text { Race } \\
\text { White } \\
\text { Black }\end{array}$ & $\begin{array}{l}52.6 \\
39.4\end{array}$ & $\begin{array}{r}279 \\
38\end{array}$ & 1 & 1.838 \\
\hline $\begin{array}{l}\text { Age } \\
16-29 \text { years old } \\
30-44 \text { years old } \\
45-54 \text { years old } \\
55 \text { years old or older }\end{array}$ & $\begin{array}{l}58.4 \\
42.1 \\
49.2 \\
55.8\end{array}$ & $\begin{array}{r}120 \\
95 \\
63 \\
43\end{array}$ & 3 & $7.848^{d}$ \\
\hline $\begin{array}{l}\text { Collar color } \\
\text { White collar } \\
\text { Blue collar }\end{array}$ & $\begin{array}{l}66.7 \\
20.9\end{array}$ & $\begin{array}{l}213 \\
110\end{array}$ & 1 & $58.962^{f}$ \\
\hline $\begin{array}{l}\text { Occupational group } \\
\text { Professional, technical and managerial } \\
\text { Clerical and sales } \\
\text { Operatives and kindred workers } \\
\text { Service workers, excluding private } \\
\text { household workers }\end{array}$ & $\begin{array}{l}70.3 \\
64.7 \\
15.2 \\
30.4\end{array}$ & $\begin{array}{r}74 \\
139 \\
59 \\
46\end{array}$ & 3 & $65.465^{f}$ \\
\hline $\begin{array}{l}\text { Industry group } \\
\text { Manufacturing } \\
\text { Wholesale and retail trade } \\
\text { Finance, insurance, and real estate } \\
\text { Services }\end{array}$ & $\begin{array}{l}27.3 \\
65.8 \\
63.3 \\
57.4\end{array}$ & $\begin{array}{r}73 \\
73 \\
30 \\
115\end{array}$ & 3 & $26.107^{f}$ \\
\hline $\begin{array}{l}\text { Union membership } \\
\text { Worker belongs to a union } \\
\text { Worker does not belong to a union }\end{array}$ & $\begin{array}{l}36.9 \\
56.1\end{array}$ & $\begin{array}{r}84 \\
239\end{array}$ & 1 & $8.383^{e}$ \\
\hline $\begin{array}{l}\text { Number of workers at worker's place of } \\
49 \text { or less } \\
50-499 \\
500 \text { or more }\end{array}$ & $\begin{array}{l}\text { employment } \\
58.4 \\
55.9 \\
34.8\end{array}$ & $\begin{array}{r}137 \\
102 \\
69\end{array}$ & 2 & $11.051^{e}$ \\
\hline
\end{tabular}

a. Farm workers were excluded.

b. Managerial workers $(n=19)$ were combined with professional and technical workers $(n=55)$. Sales workers $(n=17)$ were combined with clerical workers $(n=122)$. Otherwise, occupational groups with less than 30 women were omitted from table and computations.

c. Industry groups with less than 30 women were omitted from table and computations.

d. $\mathbf{p}<.05$.

e. $p<.01$.

f. $p<.001$.

The patterns of relationships observed in Table 2 were similar for the income discrepancy in relation to both expected and observed income. The major exception to this similarity was that white women were significantly more discriminated against than black women as indicated by the ratios of discrepancies over expected and observed values 
(formulae 2 and 3). When estimated by any of the three formulae, discrimination with regard to the Quality of Work Index exhibited almost exclusively nonsignificant associations with the demographic and occupational variables in Table 2.

In view of the obvious confounding of the five occupational variables, a Multiple Classification Analysis (Sonquist, 1970) was employed to determine which of the variables were more closely related to the income discrepancies when the effects of the other variables were removed. The multiple $\mathrm{R}$ between the five occupational predictors and the income discrepancies was .52. The beta weights of the five predictors were .53 for major occupational group, .24 for major industry group, .19 for size of place of employment, .15 for union membership, and .12 for collar color. The form of the relationship between each predictor and the adjusted mean discrepancies did not differ from the first-order relationships as suggested in Table 3.

(3) To what extent are objectively measured sex inequalities related to reports of perceived sex discrimination?

The data indicated that most women workers were discriminated against with regard both to their income and to the quality of their jobs, but only $7.9 \%$ reported differential treatment when asked, "Do you feel in any way discriminated against on your job because you are a woman?" Furthermore, perceived sex discrimination was not significantly associated with the discrepancy scores computed by any of the three formulae for either reward measure. Objective discrimination as measured in this study was therefore unrelated to perceived discrimination.

(4) To what extent are reward inequalities related to the satisfaction of women with their jobs?

Table 3 shows the correlations between the study's discrimination measures and attraction to the job as reflected in several job satisfaction measures. Quality of Work discrepancy scores computed by all three formulae were significantly associated both with overall job satisfaction as reflected in the Jobsat ' 70 scores and with job satisfaction on 


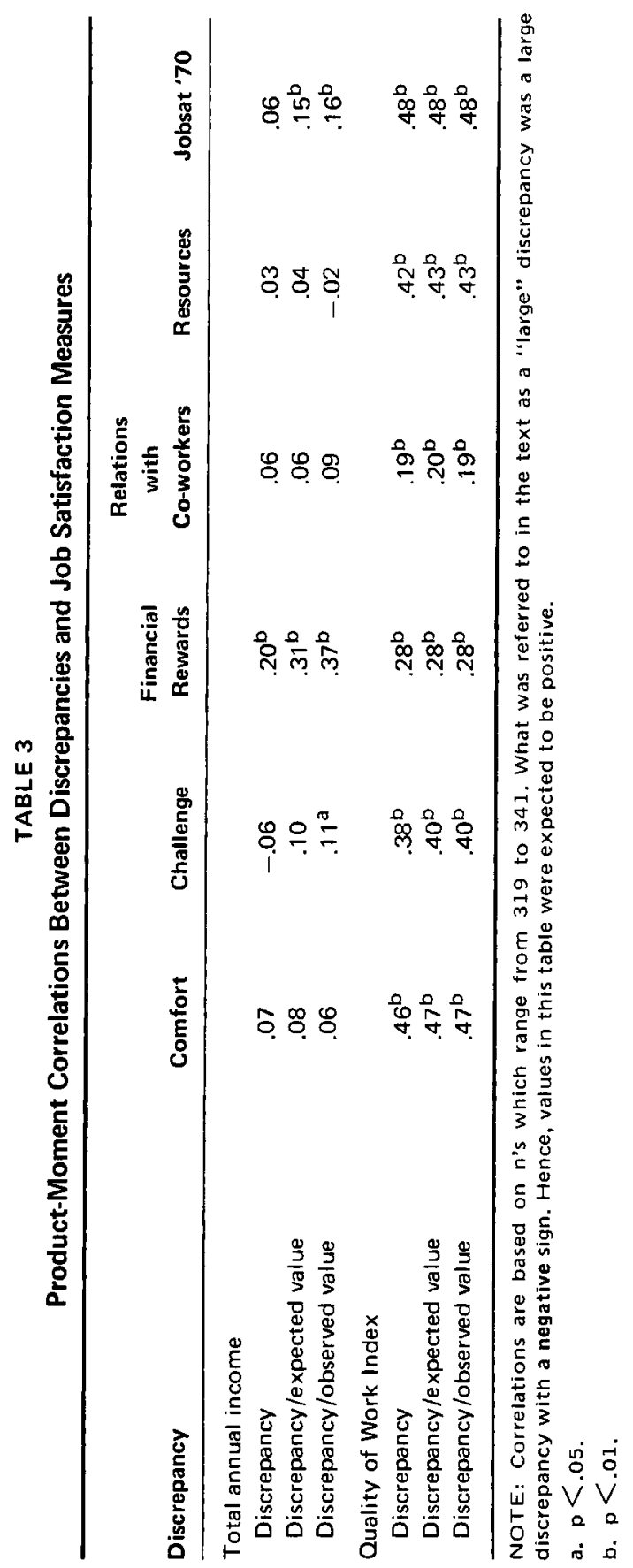


the specific dimensions of comfort, challenge, financial rewards, relations with co-workers, and resources. On each of the measures, women who were more discriminated against in terms of the quality of their jobs were less satisfied with their jobs than other women.

The associations between economic discrimination and job satisfaction were more circumscribed. Women who were most economically discriminated against as indicated by all three of the economic discrimination estimates were significantly more likely than others to be dissatisfied with the financial aspects of their jobs. Whether the economic discrepancy measures were significantly associated with overall job satisfaction as measured by Jobsat ' 70 depended upon the computational formula upon which these measures were based. The psychological implications of the income discrepancy measures that took into account neither observed nor expected income were limited. A $-\$ 1,000$ discrepancy might, for example, be of more consequence to a woman making $\$ 6,000$ a year than to one making $\$ 20,000$. The data showed a tendency, albeit small, for the income discrepancy ratios to be more closely related to overall job satisfaction and satisfaction with financial rewards than were the discrepancy scores which did not take expected or observed values into account.

\section{DISCUSSION}

(1) Extent of discrimination against female workers. The multiple regression was used to divide the sex differentials in occupational rewards into a legitimate component, based on ideologically founded control variables, and an illegitimate component, including sex discrimination. The mean difference between men and women in observed incomes, without the imposition of controls, was $-\$ 4,372$. Only $-\$ 914$ of this difference could be attributed to the achievement factors 
measured. The remaining $-\$ 3,458$ represented, in part at least, a disparity caused by illegitimate or discriminatory factors. As noted, these figures represent provisional estimates, since several methodological problems probably caused the legitimate component to be underestimated.

The problem of underestimating the legitimate component begins with the selection of variables to represent the achievement ideology. Neither direct measures of performance, nor direct measures of an individual's abilities and skills were available. With the measures of the achievement ideology both incomplete and indirect, estimation of the impact of legitimate achievement factors on occupational rewards in general and on sex differences in particular was, in all likelihood, too low. The possibility of additional error in relating achievement variables to occupational rewards occurred because discrepancy indices of discrimination were generated by a multiple regression that was based on the restrictive assumptions of linear relationships and no interaction.

Interpreted in the light of these statistical qualifications, the data nevertheless point to significant discrepancies between the actual occupational rewards that women received and the occupational rewards they ought to have received based on their achievement. The legitimate achievement factors determining the allocation of income were differentially applied to equally qualified men and women. Most women received far less income than they ought to have received.

The argument is often made that even though women earn less than equally qualified men, this difference is offset by the better working conditions supposedly enjoyed by women. There was, however, no evidence of "compensating" favoritism in terms of the quality of the job. Rather, the discrepancy scores based on the Quality of Work Index followed the same trend as those measuring annual income: women had worse jobs than equally qualified men, worse than they ought to have had based on their achievement. 
(2) Demographic and occupational distributions of reward inequalities. The observed associations between discrimination and such demographic variables as age and race make it difficult to interpret the discrepancy scores solely in terms of sex discrimination. The discrepancy scores reflect all forms of discrimination including age and race as well as sex. While they provide estimates of sex differences in the amount of total discrimination experienced, they may not be read as a wholly valid measure of discrimination based on sex per se.

Among the occupational control variables, those associated with social status yield meaningful differences. For example, financial discrimination against women (in the sense of treatment discrimination) was a greater problem for women in higher-status and in white-collar occupations. Whether the status variable would have the same significance for access discrimination is not known at this point.

(3) Objective and perceived discrimination. Given the evidence of objective discrimination against about $95 \%$ of women workers, the critical question is why only $7.9 \%$ reported discrimination on their jobs. Many factors may contribute to this inconsistency. Women may not know what equivalently qualified men are paid elsewhere, especially in other occupations. They may attribute some of the disparity to factors they regard as legitimate. They may compare themselves to other women rather than to men. They may believe that, in principle, men and women should receive unequal occupational rewards. They may attribute discrimination to factors such as age and race rather than to sex. Or they may restrict the term discrimination to instances in which discrimination is consciously planned and executed by some organizational decision maker.

(4) Correlates of objective discrimination. As expected, the measures of financial discrimination correlated significantly with satisfaction with financial rewards but not with other components of job satisfaction. In contrast, measures 
of discrimination in terms of overall quality of work, a quite general index, were significantly associated with all measures of job satisfaction.

There was, in general, considerable slippage among the several different types of variables examined: observed discrimination, perceived discrimination, and job satisfaction. The relationship between objective and perceived discrimination was nil, and that between objective discrimination and job satisfaction was modest. These observed relationships might, however, be quite time-bound. Currently many political and social action groups interested in the status of American women are helping women become increasingly conscious of the discrimination they face and less tolerant of inequitable treatment. In future years, the associations among objective discrimination, perceived discrimination and job attitudes may be greater and more consistent than at present. Moreover, the possibility arises of a substantial future increase in the currently small number of women reporting discrimination on their jobs-discrimination which the present study indicates they have every right to report.

\section{REFERENCES}

DORNBUSCH, S. M. (1966) “Afterword," pp. 204-219 in E. E. Maccoby (ed.) The Development of Sex Differences. Stanford, Calif.: Stanford Univ. Press.

QUINN, R. P., J. M. TABOR, and L. K. GORDON (1968) The Decision to Discriminate. Ann Arbor: University of Michigan Institute for Social Research. QUINN, R. P., S. SEASHORE, T. MANGIONE, D. CAMPBELL, G. L. STAINES, and M. McCULLOUGH (1971) Survey of Working Conditions. Washington, D.C.: Government Printing Office.

REISS, A. J., Jr., O. D. DUNCAN, P. K. HATT, and C. C. NORTH (1961) Occupations and Social Status. New York: Free Press.

SONQUIST, J. A. (1970) Multivariate Model Building. Ann Arbor: University of Michigan Institute for Social Research. 